\title{
A Review and Reflection on Inventory Management of Perishable Products in a Single- echelon Model
}

\author{
Linh N. K. Duong
}

Department of Business Information Systems,

Auckland University of Technology,

Auckland, New Zealand

Email: linh.duongnguyenkhanh@gmail.com

Lincoln C. Wood

Department of Business Information Systems,

Auckland University of Technology,

Auckland, New Zealand

and

School of Information Systems, Curtin University,

Perth, Australia

Email: Lincoln.Wood@aut.ac.nz

William Y. C. Wang

Department of Business Information Systems,

Auckland University of Technology,

Auckland, New Zealand

Email: william.wang@aut.ac.nz

\begin{abstract}
This paper reviews research on single-echelon inventory management of perishable products using the continuous review model. A steady progression of research in this area has included a range of parameters and is reaching a saturation point where models appear effective and cover a range of realistic situations for single-echelon management. However, research has rested on the assumption that a total cost or profit metric should be used when answering the replenishment questions of when and how much to order. This total cost/profit metric is less appropriate when considering a holistic or systemic modeling of the company where the balance in measurements between departments and the continuous improvement are a priority. From this perspective, we outline concerns with existing approaches using a total cost/profit metric when applied to a company. Instead of using approximation methods to optimize total costs/profits in a single department, we assert that managers should focus on multi-metric performance to improve system-wide results. In this paper, we present a method to compare the single-echelon replenishment model using multi-metric performance measures and those with the traditional total cost/profit metric.
\end{abstract}

\section{Keywords}

Performance metrics, inventory control, perishability, continuous review, deterioration

\section{Biographical notes}

Linh Nguyen Khanh Duong is a Ph.D. student in Supply Chain Management at the Auckland University of Technology, New Zealand. He has worked in Supply Chain Management field since 2007 for dairy and pharmaceutical companies in Vietnam. He also has joined many projects on distribution management systems, inventory management, and production 
This is a copy of the 'post-print' (i.e., final authors' copy, after referee comments have been addressed):

Duong, L.N.K., Wood, L.C., and Wang, W.Y.C. (in press). A review and reflection on inventory management of perishable products in a

single-echelon model, International Journal of Operational Research.

management. He is also a Visiting Lecturer at some at The University of Technology, The Ho Chi Minh University of Food Technology in Vietnam.

Lincoln C. Wood is a Senior Lecturer of Operations and Supply Chain Management at the Auckland University of Technology, New Zealand and an Adjunct Research Fellow at Curtin Business School, Australia. He received the 2009 Council of Supply Chain Management Professional's (CSCMP) Young Researcher Award (Chicago, USA), the Outstanding Research Award at the 2010 International Higher Education Conference (Perth, Australia), and is coLeader on a competitive grant from the Australian Office of Learning and Teaching for a gamified virtual environment for supply chain education. He has published in leading international journals including Transportation Research Part B: Methodological, International Journal of Operations \& Production Management, The Service Industries Journal, Journal of Performance of Constructed Facilities, and Habitat International. His research interests include operations and supply chain management; quality; service operations; gamification; and educational, authentic, virtual environments.

William Y.C. Wang is an Associate Professor and has supervised research projects and provided industrial consultancy in Australasia and Asian regions regarding supply chain management, global supply chain planning, and business process re-engineering with the experiences of being an IT Engineer and Corporate Consultant. He also has experiences in practical projects in Enterprise Systems such as the planning of implementing SAP and MS Dynamics. These researches have specifically highlighted the interdisciplinary issues related to B2B integration, enterprise systems adoption and maintenance, and supply chain configuration for large firms and SMEs. Those are both quantitative and qualitative. He also serves on the editorial board/advisory board of several international journals. His papers appear in Information Systems Journal, International Journal of Production Economics, International Journal of Production Research, Supply Chain Management - an International Journal, International Journal of Production Planning and Control and proceedings of international conferences.

\section{INTRODUCTION}

For almost organizations, the control and flow of materials from suppliers to end users is a key problem that can significantly influence cost and service levels. The activities associated with controlling this flow are referred to as supply chain management, which is perhaps the most challenging area in many business strategic issues (Christopher, 2013). A basic supply chain model comprises five key nodes: suppliers, manufacturers, distributors, retailers, and customers. The supply chain management aims to supply the right quantity and quality product to the customer and location at the right time. Failing on any of these conditions creates an unsuccessful supply chain system. Careful inventory management enables firms to meet demand variability, to become more flexible in their production scheduling, to safeguard against variability in material delivery times, or to take advantage of economic lot sizing (Ramanathan \& Ramanathan, 2014). Supply chain managers rely on multi-echelon models to manage inventory over different facilities or locations. However, for perishable products, single-echelon models remain crucial and form the foundation for the more realistic multiechelon models.

Rudimentary inventory management models frequently assume that products have an infinite lifetime. However, there are many products with strictly finite lifetimes indicating their value decreases with time. Goyal and Giri (2001) classify such products as facing either 'obsolescence' (loss of value because of rapid changes in technology or introducing new products; e.g., high-tech products); or 'deterioration', where the loss of value is due to damage 
or other decrease in value over time and this includes 'perishable' products with an expiry date (e.g., milk). Other products (e.g., gasoline) are 'decaying' products as, while having no expiration date, their quality decreases during storage. Pahl and Voß (2014) observe the terms deterioration and perishability are used interchangeably, and henceforth we follow this practice.

Inventory policy decisions can impact cost pressures and service levels. Retailers often expand the selection of brands and increase the product variety; while this provides greater consumer choice, it increases the inventory costs and the risk of customers' dissatisfaction during shortage situations (Bijvank \& Vis, 2012). Conceptually, managing this trade-off is simple, yet models frequently make different assumptions about how to manage the shortage situations; e.g., allowing backorders.

Inventory management research usually uses a 'total cost' or 'total profit' metric as an objective function in inventory management models, allowing the impact of many business processes to be considered simultaneously. However, Franco-Santos, Lucianetti, and Bourne (2012) study the measurement of company performance and state that in practice, companies do not assess financial performance alone; thus, the sole use of financial performance indicators may not always be valuable. Similarly (but on a broader scale), Bulsara, Qureshi, and Patel (2014) review the literature on supply chain performance measurement and state that given the multidimensional nature of supply chains, performance metrics for supply chain management should similarly be multidimensional rather than optimizing a single (total) function. Therefore, we consider the use of alternate performance metrics in continuous review models for inventory management of perishable products.

This paper provides an alternative perspective on perishable inventory theory, which conforms to the multidimensional nature of supply chains and real businesses. In this research, single-echelon and continuous review models are studied. We first evaluate the characteristics of these models, evaluate the changes in parameters used, and summarize our conclusions. Second, we reflect on the challenges of single-metric evaluations. Third, we propose the application of multidimensional performance metrics as an alternate.

\section{CHARACTERISTICS OF PERISHABLE INVENTORY PROBLEM}

An inventory management model defines time and quantity for replenishment; perishable products commonly use one of the four replenishment policies; viz., continuous review, periodic review, economic order quantity (EOQ), or economic production quantity (EPQ). The continuous review model is popular because it requires less safety stock for the same customer service level, and it enables managerial interventions to support service levels (van Donselaar \& Broekmeulen, 2014). Development of automated identification technology (e.g., Radio Frequency Identification) supports continuous review in practice (Ketzenberg, Bloemhof, \& Gaukler, 2015) and makes this a relevant model.

A range of characteristics such as demand distribution, stock issuing model, product lifetime, replenishment lead time, and shortage situations can be accommodated. Fundamental policies include:

- (s, S), when the inventory reaches the level $s$ (a 'trigger' level), an order is placed to bring the inventory back to the predetermined level $S$ (the 'target' level); the order size is quantity $(\mathrm{S}-\mathrm{s})$. This model provides significant flexibility.

- (s, nQ) or (r, nQ), whenever the inventory reaches level $s$ or $r$, an order quantity $n$ times a predetermined $Q$ (order quantity) is placed where $n$ is a multiple equal to or greater than 1. This accommodates ordering in batches.

- $(\mathrm{S}-1, \mathrm{~S})$, in this model, whenever the inventory decreases by one unit because of the demand or loss of stock, an order is placed to bring the level to $\mathrm{S}$. This model is preferred when lead times are zero and ordering cost is low. 
This is a copy of the 'post-print' (i.e., final authors' copy, after referee comments have been addressed):

Duong, L.N.K., Wood, L.C., and Wang, W.Y.C. (in press). A review and reflection on inventory management of perishable products in a

single-echelon model, International Journal of Operational Research.

\section{Demand Distribution}

Continuous review models should reflect the underlying demand pattern or demand distribution that the firm seeks to satisfy. The demand pattern is treated as either deterministic or stochastic. In deterministic problems, demand is known with certainty; e.g., demand is a fixed rate. The optimal ordering policies of EOQ and EPQ are used in deterministic demand models (Pahl \& Voß, 2014). The assumption of deterministic demand simplifies the problem but has limited application as it is uncommon to predict exact demand in real situations.

When demand is uncertain or unknown (e.g., at the start of the day a greengrocer does not know how many apples will be purchased), stochastic models are used. Most research uses the Poisson distribution where the time interval between two demands forms a Poisson process, and requirement is a single unit per period, reflecting a limitation of Poisson demand. (Interested readers are referred Ross (2006) for detailed definitions and review of the Poisson process.) As an example, Alizadeh, Eskandari, and Sajadifar (2014) study a (S - 1, S) inventory system with Poisson demand, positive lead time, and propose an enumeration algorithm to deal with the complexity of reaching an optimal inventory policy.

Real firms rarely face demand of a single unit per period, limiting the practical utility of such models and leading researchers to consider the use of compound Poisson demand distribution to overcome this limitation. Here, the interval time between two demands follows Poisson process and the demand size follows an exponential process; in each period, the demand can exceed a single unit, making compound Poisson demand distribution more realistic than other demand distributions. The compound Poisson distribution has many advantages due to the simplicity and appeal of using a standard statistical distribution (Babai, Jemai, \& Dallery, 2011). Molana, Davoudpour, and Minner (2012) consider an (r, nQ) model with compound Poisson demand, and the order-up-to-level is approximated by using upper and lower bounds.

Some researchers assume that unit demand follows a renewal process where the times between two successive demands are independent and identically distributed. Kalpakam and Sapna (1996) present the use of Markov renewal techniques to solve complex problems relating to perishable inventory with renewal demands, exponential lead time, and a constant deterioration rate. Liu and Lian (1999) construct a renewal demand process; Lian, Liu, and Zhao (2009) incorporate a Markovian renewal demand model where the inter-demand time is distributed. Lian et al. (2009) demonstrate an optimal ordering model is possible, although their results are achieved using approximation only.

Inventory management models for perishable products depend on demand characteristics. These observations reconfirm a key finding in Nahmias (2011): when demand is random, the optimal ordering problem is difficult to attain as the lifetime is more than one period, and so no replenishment model can eliminate or prevent the loss of inventory due to perishability. The mathematical model for this problem must contain the inventory position of each age group. Therefore, the focus is on finding near-optimal solutions or approximations, and many assumptions are still being extended now; e.g., demand, lead time and lifetime distribution, or multiple products (Pahl \& Voß, 2014).

\section{Stock Issuing Policy}

Products are stored until required or disposal (e.g., outdated stock); the stock issuing policy is crucial when considering products with a finite lifetime. The two most commonly used stock issuing policies are First-In-First-Out (FIFO) and Last-In-Fist-Out (LIFO). In FIFO, the product arrives in warehouse first will be delivered to customers first in the order of arrival; in LIFO, the product that has most arrived in the warehouse will be delivered to customers first. For simplicity, assuming that the product lifetime starts when the product arrives at the warehouse. Customers prefer LIFO to FIFO policies as it provides the freshest products. In the technical view, Parlar, Perry, and Stadje (2011) compare two policies and show that the FIFO 
This is a copy of the 'post-print' (i.e., final authors' copy, after referee comments have been addressed):

Duong, L.N.K., Wood, L.C., and Wang, W.Y.C. (in press). A review and reflection on inventory management of perishable products in a

single-echelon model, International Journal of Operational Research.

dominates LIFO when considering the combination of all operational costs. However, when the holding cost is high, or the purchase cost is low, LIFO dominates FIFO. Most research uses the FIFO policy.

\section{Lifetime}

Many articles assume that a product can be kept indefinitely to meet the demand without losing its value. However, there are many products, which have a finite lifetime, lose value over time and will expire worthless at some point. The products, which are stored until a predetermined time and then are destroyed, have a fixed lifetime. Another category of products have an unknown time until they expire without value; these products have a stochastic lifetime. The decay rate of fresh vegetables depends on temperature and other climatic conditions relating to storage, providing a good example of a product with stochastic lifetime.

It is more common in practice for products to have a finite lifetime; however, modelling of a finite lifetime is more complex than for infinite lifetime and models must be expanded to more dimensions to accommodate this (Pahl \& Voß, 2014). Olsson and Tydesjö (2010) prove a problem with fixed lifetime is more complex than with stochastic lifetime as the Markovian property cannot be used to describe the stock on-hand. Kouki, Sahin, Jemaï, and Dallery (2013) study the effectiveness of (r, Q) inventory systems for perishable items with fixed lifetime and lead time. They note that the fixed lifetime perishable problem under either continuous or periodic review systems is complex when the lifetime exceeds two units. Despite this complexity, accommodating finite lifetime is important as Gürler and Özkaya (2008) demonstrate that accounting for stochastic lifetime reduces total operations cost. Therefore, to reduce the complexity of problem, most researchers assume that products have a stochastic lifetime and newly arrived products are fresh; there is a tendency towards heuristic approaches providing approximate results as this can help overcome the problems complexity.

\section{Lead time}

Incorporating lead time in continuous review models is challenging as products age when in stock and while on order and there are an outstanding number of orders during the lead time. The simplifying assumption of a zero lead time (i.e., immediate delivery on order) removes these challenges.

Positive lead time increases the relevance and complexity of the model; this is why it is infrequently considered (Kouki et al., 2013). Early studies (e.g., Ravichandran (1995)) of a single perishable item with Poisson demand, deterministic positive lead time, and lifetime under (s, S) continuous review system demonstrate that when such realistic assumptions (e.g., positive lead time and deterministic lifetime) are used the model becomes difficult to solve. Alizadeh et al. (2014) analyze an (S - 1, S) perishable system with Poisson demands and nonzero lead time; they use simulation to study the impact of lead time. Perishable inventory systems with positive lead time are complex problems when stochastic elements are introduced; this has led to most researchers using an approximation of optimal results or simulation.

\section{Shortage Situation}

When demand cannot be immediately met, a model may use either 'lost sales' or 'backorders'. For instance, a consumer at a supermarket finds that bread is out of stock; if the customer waits until the store has bread again, it is a backorder situation. Alternatively, if the customer leaves the store, it is a lost sales situation.

Consumer behavior during shortage periods is important. When faced with a shortage situation, consumers may find, try or evaluate, and perhaps eventually prefer an alternative product. From manufacturers' perspective, this consumer may be lost forever, reducing the 
long-term value of the product line. Repeated shortages negatively impact retailers as they lose customers, and the manufacturer faces lost sales. Particularly, consumers are willing to substitute another perishable product if the preferred one is unavailable (van Donselaar \& Broekmeulen, 2014). Therefore, inventory management decisions should account for consumer behavior and substitutions that they may make.

A significant body of research uses backorder, lost sales or both. However, research analyzing consumer behavior proves that unfulfilled demand most commonly results in lost sales. Models with lost sales have received greater attention. The review by Bijvank and Vis (2011) demonstrates that little is known about optimal replenishment models accounting for lost sales under these circumstances. In the backorder model, the inventory position must account for the demand during the lead time; in the lost sales model, the inventory position does not. Therefore, models with lost sales are more difficult to analyze than those with backorders, making them more amenable to solve using approximation approaches.

A further complication is due to the difficulty in defining the cost of lost sales as it includes intangible costs; e.g., goodwill. To substitute for the lost sales cost, researchers tend to use the customer service level; similar to the proportion of met demand in the "fill rate" or the "ready rate", it is the proportion of time when stock on-hand is positive (Larsen \& Thorstenson, 2014). The customer service level can be considered as either the mean service level constraint model (controlling the average service), or the minimal service level constraint model (controlling the minimum service level over the planning horizon) (Chen \& Krass, 2001). The customer service level also can be defined in two ways. The first option is to use the probability of no shortage during replenishment cycle. The second option, useful from both an analytic and practical/management perspective, is defined as the proportion of replenishment cycles which end with all customer demand satisfied (Estellés-Miguel, Cardós, Albarracín, \& Palmer, 2014).

Further investigation of alternate customer behaviors (e.g., substituting products or frequenting substitute stores) during shortage situations has been called for by Bijvank and Vis (2011). Such substitution has a significant influence on optimal replenishment models and requires more attention. Estellés-Miguel et al. (2014) suggest that improving approximation methods is important as exact methods for solving these models require computationally intensive techniques. Thus, approximation methods are more commonly used.

\section{CONTINUOUS REVIEW REPLENISHMENT IN A SINGLE-ECHELON}

This research builds on the reviews of perishable inventory management from Goyal and Giri (2001) (including papers until 2001) and from Bakker, Riezebos, and Teunter (2012) (papers from 2001 to 2011). We updated with new articles published between 2011 until March 2014 and focused on the perishable inventory under continuous review for a single-echelon model. First, to find the relevant papers, the ABI ProQuest database was searched with a predefined list of keywords. These keywords include deteriorat* (to capture deterioration/deteriorating/deteriorated); perish* (to capture perishable/perishability/perishing); decay* (to capture decay/decayed/decaying); lifetime; shelf life; inventory; stock control; and continuous review. At this phase, 78 papers were selected (from journals listed in Table 1). 
Table 1: No. of paper by journal

\begin{tabular}{|c|c|}
\hline Journal & Number \\
\hline Operations Research & 8 \\
\hline European Journal of Operational Research & 7 \\
\hline International Journal of Production Economics & 7 \\
\hline Computers \& Industrial Engineering & 4 \\
\hline Computers \& Operations Research & 3 \\
\hline International Journal of Operational Research & 3 \\
\hline Stochastic Analysis and Applications & 3 \\
\hline Annals of Operations Research & 2 \\
\hline Applied Mathematical Modelling & 2 \\
\hline International Journal of Information and Management Sciences & 2 \\
\hline International Journal of Production Research & 2 \\
\hline Journal of the Operational Research Society & 2 \\
\hline Manufacturing \& Service Operations Management & 2 \\
\hline Mathematical Problems in Engineering & 2 \\
\hline Naval Research Logistics & 2 \\
\hline Production and Operations Management & 2 \\
\hline Advanced Modeling and Optimization & 1 \\
\hline African Journal of Business Management & 1 \\
\hline Computers and Mathematics with Applications & 1 \\
\hline Engineering Costs and Production Economics & 1 \\
\hline International Journal of Advanced Manufacturing Technology & 1 \\
\hline International Journal of Approximate Reasoning & 1 \\
\hline International Journal of Computer Applications & 1 \\
\hline International Journal of Information Systems and Supply Chain & \\
\hline Management & 1 \\
\hline International Journal of Mathematics and Mathematical Sciences & 1 \\
\hline International Journal of Operations \& Production Management & 1 \\
\hline International Journal of Revenue Management & 1 \\
\hline International Journal of Systems Science & 1 \\
\hline Journal of Applied Mathematics \& Decision Sciences & 1 \\
\hline Journal of Computational and Applied Mathematics & 1 \\
\hline Journal of Operations Management & 1 \\
\hline Journal of Service Science \& Management & 1 \\
\hline Management Science & 1 \\
\hline Mathematical and Computer Modelling & 1 \\
\hline Mathematical Methods of Operations Research & 1 \\
\hline Modelling and Simulation in Engineering & 1 \\
\hline Perspectives in Applied Mathematics & 1 \\
\hline Probability in the Engineering and Informational Sciences & 1 \\
\hline Production Planning \& Control & 1 \\
\hline Statistics & 1 \\
\hline The South African Journal of Industrial Engineering & 1 \\
\hline
\end{tabular}

Secondly, the titles and abstracts were checked to ensure they were articles on continuous review and involved a model for perishable products in a single-echelon. For example, we excluded papers focusing on multi-echelon models; those with other intents or purposes (e.g., review papers); and those which do not develop a model or formula for the management of perishable inventory. The remaining 26 papers are summarized here. 
To our knowledge, perishable inventory management under continuous review for a singleechelon model has been extensively researched and addressed since 1980; where mentioned in the earlier research, the problem is only discussed and not modeled. Therefore, we summarize research from 1980. This stream of research showed a peak in interest and publication of seven papers from 1995 to 1999 (Table 2). Over this period, more constraints were relaxed as the theories were more fully developed.

Table 2. No. of paper published by decade

\begin{tabular}{ll}
\hline Year & Number of paper \\
\hline $1980-1984$ & 1 \\
$1985-1989$ & 2 \\
$1990-1994$ & 2 \\
$1995-1999$ & 7 \\
$2000-2004$ & 2 \\
$2005-2009$ & 6 \\
$2010-2014$ & 6 \\
\hline
\end{tabular}

To make the models more tractable, a zero lead time has usually been assumed. Two early articles [viz., Weiss (1980) and Kalpakam and Arivarignan (1988)] assumed lead time as zero when continuous review was initially investigated. Thereafter, the lead time was usually assumed as zero when research examined a new distribution of demand; e.g., batch renewal or compound Poisson distribution (Table 3). When lead time is zero, the inventory position is added immediately whenever an order is placed, and there is no outstanding order during the review period. Later on, this assumption of zero lead time is relaxed to make the problem more realistic. A constant lead time makes the problem more complicated, and this set of conditions has been more thoroughly examined only since 2008 (Table 4).

Table 3. Paper with zero lead time

\begin{tabular}{lllll}
\hline Work & Repl & Exc & Lifetime & Dem \\
\hline Weiss (1980) & $(\mathrm{s}, \mathrm{S})$ & $\mathrm{B} / \mathrm{L}$ & $\mathrm{D}$ & $\mathrm{P}$ \\
\hline Kalpakam and Arivarignan $(1988)$ & $(\mathrm{s}, \mathrm{S})$ & $\mathrm{L}$ & $\exp$ & $\mathrm{P}$ \\
\hline Liu (1990) & $(\mathrm{s}, \mathrm{S})$ & $\mathrm{B}$ & $\exp$ & $\mathrm{P}$ \\
\hline Liu and Lian (1999) & $(\mathrm{s}, \mathrm{S})$ & $\mathrm{B}$ & fix & $\mathrm{R}$ \\
\hline Lian and Liu (1999) & $(\mathrm{s}, \mathrm{S})$ & $\mathrm{B}$ & $\mathrm{PH}$ & $\mathrm{BR}$ \\
\hline Kalpakam and Shanthi (2001) & $(\mathrm{S}-1, \mathrm{~S})$ & $\mathrm{L}$ & $\mathrm{exp}$ & $\mathrm{P}$ \\
\hline Lian and Liu (2001) & $(\mathrm{s}, \mathrm{S})$ & $\mathrm{B}$ & fix & $\mathrm{BR}$ \\
\hline Lian et al. (2005) & $(\mathrm{s}, \mathrm{S})$ & $\mathrm{B}$ & $\mathrm{PH}$ & $\mathrm{PH}$ \\
\hline Gurler and Ozkaya (2008) & $(\mathrm{s}, \mathrm{S})$ & $\mathrm{B}$ & $\mathrm{sto}$ & $\mathrm{BR}$ \\
\hline Lian et al. (2009) & $(\mathrm{s}, \mathrm{S})$ & $\mathrm{B}$ & $\exp$ & $\mathrm{RM}$ \\
\hline Baron and Berman $(2010)$ & $(\mathrm{s}, \mathrm{S})$ & $\mathrm{L}$ & $\exp$ & $\mathrm{cP}$ \\
\hline
\end{tabular}


Table 4. Paper with positive lead time

\begin{tabular}{llllll}
\hline Work & Repl & Exc & LT & Lifetime & Dem \\
\hline Schmidt and Nahmias (1985) & $(\mathrm{S}-1, \mathrm{~S})$ & L & D & D & P \\
\hline Kalpakam and Sapna (1994) & $(\mathrm{s}, \mathrm{S})$ & L & exp & exp & P \\
\hline Kalpakam and Sapna (1995) & $(\mathrm{S}-1, \mathrm{~S})$ & L & D & exp & P \\
\hline Chiu (1995) & $(\mathrm{s}, \mathrm{nQ})$ & $\mathrm{B}$ & $\mathrm{D}$ & $\mathrm{D}$ & $\mathrm{gen}$ \\
\hline Ravichandran (1995) & $(\mathrm{s}, \mathrm{S})$ & $\mathrm{L}$ & fix & fix & $\mathrm{P}$ \\
\hline Kalpakam and Sapna (1996) & $(\mathrm{S}-1, \mathrm{~S})$ & $\mathrm{L}$ & $\exp$ & $\exp$ & $\mathrm{R}$ \\
\hline Liu and Yang (1999) & $(\mathrm{s}, \mathrm{S})$ & $\mathrm{B}$ & $\exp$ & $\exp$ & $\mathrm{P}$ \\
\hline Kalpakam and Shanthi (2006) & $(\mathrm{s}, \mathrm{S})$ & $\mathrm{L}$ & $\exp$ & $\exp$ & $\mathrm{R}$ \\
\hline
\end{tabular}

\begin{tabular}{llllll} 
Kouki et al. (2008) & $(\mathrm{s}, \mathrm{nQ})$ & $\mathrm{B}$ & fix & fix & gen \\
\hline Berk and Gürler $(2008)$ & $(\mathrm{s}, \mathrm{nQ})$ & $\mathrm{L}$ & fix & fix & $\mathrm{P}$ \\
\hline Olsson and Tydesjö $(2010)$ & $(\mathrm{S}-1, \mathrm{~S})$ & $\mathrm{B}$ & fix & fix & $\mathrm{P}$ \\
\hline
\end{tabular}

Sazvar et al. (2013) $\quad(\mathrm{s}, \mathrm{nQ}) \quad$ B $\quad$ exp sto $\quad$ exp

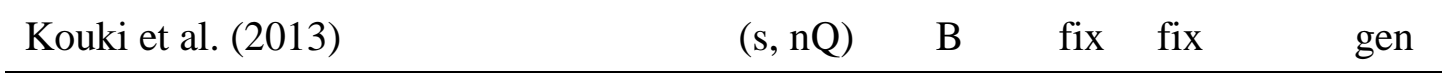

$\begin{array}{llllll}\text { Alizadeh et al. (2014) } & (\mathrm{S}-1, \mathrm{~S}) & \mathrm{B} & \text { fix } & \text { rco } & \text { Erl }\end{array}$

Van Donselaar and Broekmeulen (2014) $\quad$ (s, nQ) $\quad$ B $\quad$ fix sto gen

(Repl: Replenishment model, Exc: Excess demand, Dem: Demand, LT: Lead time, B: Backorder, L: Lost sales, exp: exponential, PH type: Phase type, D: Deterministic, P: Poisson, R: Renewal, BR: Batch renewal, RM: renewal Markovian, cP: compound Poisson, rco: rate constant, sto: stochastic, fix: fixed, gen: general, Erl: Erlang)

Although in the lost sales case it is more difficult to find the optimal result than with backorder, the ratio of papers with lost sales and backorder is almost equal (i.e., $42 \%$ and 58\%). The models that assume full backorder are less realistic than models that assume lost sales or partial backorder. Moreover, the researchers intend to find the approximation results instead of optimal results. Later on, introducing service levels gives another approach to accommodating lost sales. Using service levels for a lost sales problem requires a limited number of outstanding orders. This approach is suggested in the study of van Donselaar and Broekmeulen (2014) and guides further research, e.g., multi-echelon modeling.

The $(\mathrm{s}, \mathrm{S})$ replenishment model is most common, used in 14 papers. The vector of inventory ages is a Markov chain, and it is relatively simple to construct an approximation for this model. The model (s, nQ), which is used for a fixed replenishment quantity, is used in six papers. The remaining six papers use the $(S-1, S)$ model, which is suitable when products are delivered in a package (e.g., liquids) or a container.

Most assume a Poisson demand distribution (11 papers). There are seven papers using renewal demand, four using general, and one each using Erlang, Phase type, Exponential, and Compound Poisson. Recently, with the increased accessibility and development of approximation methods, researchers used a wider variety of demand distributions when the 
This is a copy of the 'post-print' (i.e., final authors' copy, after referee comments have been addressed):

Duong, L.N.K., Wood, L.C., and Wang, W.Y.C. (in press). A review and reflection on inventory management of perishable products in a

single-echelon model, International Journal of Operational Research.

demand size is more than one unit size per order time, providing a more realistic model; e.g., Erlang distribution.

\section{REFLECTION ON CRITERIA USED IN SINGLE-ECHELON MODEL}

Inventory modeling involves first formulating an objective function (e.g., minimizing total cost or maximizing total profit function) for a proposed replenishment model. The decision variables in that model (e.g., reorder level) are generated when the researchers find or approximate the optimal values for the objective function, including some or all cost factors in inventory problem (e.g., holding cost). Using a total function helps the researchers quantify various elements into a single-dimensional problem, which is more easily to solve.

However, Akyuz and Erkan (2010) state that supply chains are by nature multidimensional; consequently, rather than optimizing a total function, a range of performance metrics should be used. This section accounts for this concern; we reiterate the four key concerns on optimizing a single objective function and outline why this is not necessarily a good approach. Then, we present performance metrics as an alternate to the traditional approach of optimizing the objective function.

First, the traditional approach uses the total function to generate the results. These functions are formulated based on a series of (most importantly) inventory-related costs; e.g., holding cost, ordering cost. Nevertheless, in reality, it is difficult to establish holding costs for a given period or processing costs per order. For instance, in backorder situation, it is may be possible to calculate the cost of additional transportation or the overtime labor cost used to rectify the problem; however, it is much more difficult to quantify the cost of the customers' dissatisfaction because of the late delivery or the impact on employee moral from being required to work overtime.

Second, the results are often found through the approximation approach. According to Ozer and Xiong (2008), an approximation approach should be used if it meets five criteria:

- provides a nearly optimal result (i.e., the result from approximation is not substantially different to the optimal result);

- easy to compute (i.e., the approximation result can be generated from simple calculations);

- simple to explain and use (i.e., the formula is simple to understand and the user can describe it to other users);

- $\quad$ strong (i.e., uses accurate data that are easily acquired); and,

- used to test a system (i.e., when input variables change, the system can be tested with new input).

Concentrating on the only first criterion of nearly optimal results overlooks the other criteria. Therefore, to improve our results we should understand how the approximation approach runs under these five criteria.

Third, inventory management is a part of wider company operations. Thus inventory management improvements should improve overall operations. A Planning Department may handle ordering and monitoring inventory while the Merchandising Department may handle delivering products to customers. By optimizing the total function, including the cost of customer service, the Planners define when to order and how many of each product should be held in the warehouse. This decision accounts for customer service costs. However, optimizing the total function does not provide information on how well the Merchandising Department should be serving their customers. A misunderstanding from the Merchandising Department (e.g., sending the wrong quantity) will create additional costs to satisfy customers, and the total operational costs will be increased. Hence, using total function is more suitable when focusing 
This is a copy of the 'post-print' (i.e., final authors' copy, after referee comments have been addressed):

Duong, L.N.K., Wood, L.C., and Wang, W.Y.C. (in press). A review and reflection on inventory management of perishable products in a

single-echelon model, International Journal of Operational Research.

on a single department only as it may not accommodate different departments with different objectives or metrics.

Fourth, using an objective function relies on the availability of information. However, information on demand, deterioration rates, and lead times are not always predetermined or well-known and may even change over time. As an example of the impact, unavailability of demand information can create the bullwhip effect (BWE) and higher inventory level (Lee, Padmanabhan, \& Whang, 1997).

The above reasons suggest that using a single function is not a good approach, and an alternative approach should be adopted. Perishable inventory management is similar to BWE research for two reasons. First, the information required in the supply chain (e.g., demand), is vulnerable to influence from external factors (e.g., disasters), and create demand fluctuations and BWE. Second, inventory policy is important for perishable inventory and is one of the three research streams on BWE (Nepal, Murat, \& Chinnam, 2012). Therefore, we contend that improved performance measurement can be developed by reviewing the literature on the BWE and applying this to perishable inventory models.

In review papers on BWE, the use of a single financial measurement is criticized as it only supports cost minimization rather than continuous improvement of the organization as a whole (Ahola \& Lehtinen, 2010). Towill, Zhou, and Disney (2007) insist on a multidimensional analysis of the BWE. Even if only considering a single firm, Akyuz and Erkan (2010) state that a performance metric should be exact, non-financial, actionable, simple, and in forms of ratios that allow for testing, reviewing, revising, and involving organizational learning; even within a single-echelon many managers within the echelon have different metrics against which their work is judged. Therefore, establishing performance metrics to support overall firm performance is a challenging task that requires the partnership and collaboration. Cannella, Barbosa-Póvoa, Framinan, and Relvas (2013) design a performance measurement for both single-echelon and complete supply chain systems by dividing assessment criteria into either "Internal process efficiency" or "Customer satisfaction" metrics. They then suggest five performance measures for a single-echelon supply chain management system; viz., Order Rate, Fill Rate, Average Inventory, Inventory Variance, and the Work in Progress (WIP) Variance ratio.

Our research considers the inventory management from a corporate or a company-wide perspective. As forecasts for inventory management reflect the BWE, we apply a wider set of performance metrics as suggested by Cannella et al. (2013). However, we focus on two of five measures suggested by Cannella et al. (2013); namely, Fill Rate (which is relevant to Customer service level) and Average Inventory (which is relevant to Total inventory cost) criteria. These represent both internal process efficiency and customer satisfaction criterion and will be readily understood by many supply chain managers and staffs. The Average Inventory is the mean of inventory level during an inspection time (e.g., week or month). It is frequently used in production and distribution systems to assess inventory investment and is treated as representative of internal process efficiency. The Fill Rate is a percentage of orders delivered on time and is representative of other customer satisfaction criteria.

We propose the simultaneous use of both Average Inventory and Fill Rate measurement as an alternative approach (which we term the metrics approach hereafter). As mentioned above, the approximation approach should meet five criteria before used; therefore, the alternative approach proposed here can be used when the approximation approach does not satisfy five criteria outlined in Ozer and Xiong (2008). Also, the metrics approach can be used for models highly impacted by the BWE and is, therefore, a robust measure. The results received from the metrics approach can be compared with the results from the existing research using a total function to understand the differences between the two approaches. We propose a four-step method to accomplish this. 
Step 1: An existing paper is chosen for comparison. In this section, the paper "Comparison between continuous review inventory control systems for perishables with deterministic lifetime and lead time" from Kouki et al. (2013) was chosen. This recent research uses a general demand probability distribution which can be extended; the deterministic lead time and lifetime usually make the problem more complicated; and the replenishment model ( $r, \mathrm{Q})$ is similar to the more commonly applied (s, S) model. Furthermore, the results from Kouki et al. (2013) were extracted from software to find optimal values, and these are proven to be better than past results.

Step 2: The characteristics and formulations to calculate expected results are presented. As stated in the model in Kouki et al. (2013), the problem has these characteristics:

- A single product with fixed lifetime $m$ times unit. The lead time $L$ is fixed.

- The problem is considered under the $(\mathrm{r}, \mathrm{Q})$ continuous review model, whenever the inventory level reaches the order level $r$, an order size $Q>0$ is placed.

- The product arrives fresh. The product is delivered according to FIFO model, and excess demand is fully backorder.

- The demand per unit time, $Z$, is a nonnegative random variable with mean $D$, probability distribution function $\mathrm{f}(\mathrm{z})$ and the cumulative distribution function $\mathrm{F}(\mathrm{z})$.

According to Kouki et al. (2013), the expected outdated quantity E[O] is:

$$
E[O]=\int_{0}^{r+Q-x}\left(r+Q-x-d_{m+L}\right) f_{m+L}\left(d_{m+L}\right) d d_{m+L}, \forall x \in[0, r]
$$

The expected backorder quantity $\mathrm{E}[\mathrm{S}]$ is:

$$
\begin{gathered}
E[S]=\left(1-F_{m+L}(r+Q-E[O]) \int_{r}^{\infty}\left(d_{L}-r\right) f_{L}\left(d_{L}\right) d d_{L}+F_{m+L}(r+Q-E[O]) \int_{r-E[O]}^{\infty}\left(d_{L}-r+\right.\right. \\
E[O]) f_{L}\left(d_{L}\right) d d_{L}
\end{gathered}
$$

The expected inventory level per unit time $\mathrm{E}[\mathrm{I}]$ is:

$$
E[I]=r-D L+\frac{Q}{2}+D L \frac{E[S]-E[O]}{2(Q-E[O])}
$$

Step 3: Instead of using total function, the metrics approach is defined to find the reorder level and quantity order size regarding these criteria:

The fill rate (FR); the higher the fill rate is, the better solution is:

$$
F R=1-\frac{E[S]}{E[I]}
$$

The average inventory (AI); the lower the average inventory level, the better solution is

$$
A I=E[I]
$$

Step 4: The lower bound for FR and the upper bound for AI are defined.

For the perishable inventory management, simulation supports the representation of practical problems and provides more opportunities to deal with the inherent complexity being modeled. The simulation model allows the researchers to more easily test the system performance and the impacts and the correlations of factors in the system (Bakker et al., 2012). Considering the advantages of simulation and the problems complexity, simulation as a modeling method is suggested. A simulation model helps to understand the behavior of the inventory management model. Then, a heuristic is used to find reorder point $r$ and quantity order size Q. The results are compared with the results from Kouki et al. (2013). 
This is a copy of the 'post-print' (i.e., final authors' copy, after referee comments have been addressed):

Duong, L.N.K., Wood, L.C., and Wang, W.Y.C. (in press). A review and reflection on inventory management of perishable products in a

single-echelon model, International Journal of Operational Research.

\section{CONCLUSION}

We summarized the research on the continuous review model for perishable products and presented the characteristics commonly used in a continuous review replenishment model for perishable products inventory management. Then, we provided further insight into the development of the research trends when using and combining these characteristics for a perishable inventory management system. We showed that the current trend was towards the use of more sophisticated demand distribution in the models; however, single-echelon inventory management appears to be reaching a saturation point and researchers should increasingly focus their attention on multi-echelon models.

Normally, in single-echelons, an approximation approach is used, and we highlighted our concerns regarding the application of this approach to a wider system, such as an entire enterprise. A metrics approach was introduced for a perishable inventory management system, and a process was proposed for comparing the performance and results from the metrics approach and approximation approach. The metrics approach is used when a decision is made from the view of the total company or when the approximation approach does not satisfy the five criteria presented in Ozer and Xiong (2008). The results contribute to inventory theory as this approach is more realistic as it incorporates multiple inventory characteristics and allows continuous improvement with performance metrics. The simulation results are used to develop heuristics, which provides quick solutions for changing in inventory characteristics (e.g., demand distribution) and business requirement (e.g., target fill rate).

This research proposes a method to compare the replenishment decision determined using metrics approach with that from approximating the total cost or total profit function. Future research can apply this method to other types of perishable inventory management (e.g., multiechelon, or multi-products). Cannella et al. (2013) suggest metrics with five criteria and another research direction would involve considering performance metrics with a wider range of criteria for a comprehensive comparison that may present robust solutions to improve overall corporate performance.

\section{REFERENCES}

Ahola, T., \& Lehtinen, J. (2010). Is performance measurement suitable for an extended enterprise? International Journal of Operations \& Production Management, 30(2), 181-204. doi: 10.1108/01443571011018707

Akyuz, G. A., \& Erkan, T. E. (2010). Supply chain performance measurement: A literature review. International Journal of Production Research, 48(17/18), 5137-5155. doi: 10.1080/00207540903089536

Alizadeh, M., Eskandari, H., \& Sajadifar, S. M. (2014). A modified (S - 1,S) inventory system for deteriorating items with Poisson demand and non-zero lead time. Applied Mathematical Modelling, 38(2), 699-711. doi: 10.1016/j.apm.2013.07.014

Babai, M. Z., Jemai, Z., \& Dallery, Y. (2011). Analysis of order-up-to-level inventory systems with compound Poisson demand. European Journal of Operational Research, 210(3), 552-558. doi: 10.1016/j.ejor.2010.10.004

Bakker, M., Riezebos, J., \& Teunter, R. H. (2012). Review of inventory systems with deterioration since 2001. European Journal of Operational Research, 221(2), 275-284. doi: 10.1016/j.ejor.2012.03.004

Berk, E., \& Gürler, Ü. (2008). Analysis of the (Q,r) inventory model for perishables with positive lead times and lost sales. Operations Research, 56(5), 1238-1246. doi: 10.2307/25580878

Bijvank, M., \& Vis, I. F. A. (2011). Lost-sales inventory theory: A review. European Journal of Operational Research, 215(1), 1-13. doi: 10.1016/j.ejor.2011.02.004

Bijvank, M., \& Vis, I. F. A. (2012). Lost-sales inventory systems with a service level criterion. European Journal of Operational Research, 220(3), 610-618. doi: 10.1016/j.ejor.2012.02.013

Bulsara, H. P., Qureshi, M. N., \& Patel, H. (2014). Supply chain performance measurement - An exploratory study. International Journal of Logistics Systems and Management, 18(2), 231-249. doi: 10.1504/ijlsm.2014.062328

Cannella, S., Barbosa-Póvoa, A. P., Framinan, J. M., \& Relvas, S. (2013). Metrics for bullwhip effect analysis. Journal of the Operational Research Society, 64(1), 1-16. doi: 10.1057/jors.2011.139 
This is a copy of the 'post-print' (i.e., final authors' copy, after referee comments have been addressed):

Duong, L.N.K., Wood, L.C., and Wang, W.Y.C. (in press). A review and reflection on inventory management of perishable products in a single-echelon model, International Journal of Operational Research.

Chen, F. Y., \& Krass, D. (2001). Inventory models with minimal service level constraints. European Journal of Operational Research, 134(1), 120-140. doi: 10.1016/s0377-2217(00)00243-5

Chiu, H. N. (1995). An approximation to the continuous review inventory model with perishable items and lead times. European Journal of Operational Research, 87(1), 93-108. doi: 10.1016/0377-2217(94)00060-P

Christopher, M. (2013). Logistics and supply chain management (4th ed.). London: Pearson.

Estellés-Miguel, S., Cardós, M., Albarracín, J. M., \& Palmer, M. E. (2014). Design of a continuous review stock policy. In J. C. Prado-Prado \& J. García-Arca (Eds.), Annals of Industrial Engineering 2012 (pp. 139-146). London: Springer.

Franco-Santos, M., Lucianetti, L., \& Bourne, M. (2012). Contemporary performance measurement systems: A review of their consequences and a framework for research. Management Accounting Research, 23(2), 79119. doi: 10.1016/j.mar.2012.04.001

Goyal, S. K., \& Giri, B. C. (2001). Recent trends in modeling of deteriorating inventory. European Journal of Operational Research, 134(1), 1-16. doi: 10.1016/s0377-2217(00)00248-4

Gürler, Ü., \& Özkaya, B. Y. (2008). Analysis of the (s,S) policy for perishables with a random shelf life. IIE Transactions, 40(8), 759-781. doi: 10.1080/07408170701730792

Kalpakam, S., \& Arivarignan, G. (1988). A continuous review perishable inventory model. Statistics, 19(3), 389398. doi: 10.1080/02331888808802112

Kalpakam, S., \& Sapna, K. P. (1994). Continuous review (s, S) inventory system with random lifetimes and positive leadtimes. Operations Research Letters, 16(2), 115-119. doi: 10.1016/0167-6377(94)90066-3

Kalpakam, S., \& Sapna, K. P. (1995). (S - 1,S) Perishable systems with stochastic leadtimes. Mathematical and Computer Modelling, 21(6), 95-104. doi: 10.1016/0895-7177(95)00026-X

Kalpakam, S., \& Sapna, K. P. (1996). A lost sales (S - 1,S) perishable inventory system with renewal demand. Naval Research Logistics, 43(1), 129-142. doi: 10.1002/(sici)1520-6750(199602)43:1<129::aidnav8>3.0.co;2-d

Kalpakam, S., \& Shanthi, S. (2001). A perishable inventory system with modified $(\mathrm{S}-1, \mathrm{~S})$ policy and arbitrary processing times. Computers and Operations Research, 28(5), 453-471. doi: 10.1016/s0305-0548(99)00131$\underline{8}$

Kalpakam, S., \& Shanthi, S. (2006). A continuous review perishable system with renewal demands. Annals of Operations Research, 143(1), 211-225. doi: 10.1007/s10479-006-7383-0

Ketzenberg, M., Bloemhof, J., \& Gaukler, G. (2015). Managing perishables with time and temperature history. Production and Operations Management, 24(1), 54-70. doi: 10.1111/poms.12209

Kouki, C., Sahin, E., Jemaï, Z., \& Dallery, Y. (2008). A continuous review inventory control model for perishable products having deterministic lifetime and lead time. Laboratoire Genie Industriel, Ecole Centrale Paris, Paris, France.

Kouki, C., Sahin, E., Jemaï, Z., \& Dallery, Y. (2013). Comparison between continuous review inventory control systems for perishables with deterministic lifetime and lead time. Paper presented at the Modeling, Simulation and Applied Optimization (ICMSAO), 2013 5th International Conference on.

Larsen, C., \& Thorstenson, A. (2014). The order and volume fill rates in inventory control systems. International Journal of Production Economics, 147(1), 13-19. doi: 10.1016/j.ijpe.2012.07.021

Lee, H. L., Padmanabhan, V., \& Whang, S. (1997). Information distortion in a supply chain: The bullwhip effect. Management Science, 43(4), 546-558. doi: 10.2307/2634565

Lian, Z., \& Liu, L. (1999). A discrete-time model for perishable inventory systems. Annals of Operations Research, 87(0), 103-116. doi: 10.1023/a:1018960314433

Lian, Z., \& Liu, L. (2001). Continuous review perishable inventory systems: Models and heuristics. IIE Transactions, 33(9), 809-822. doi: 10.1080/07408170108936874

Lian, Z., Liu, L., \& Neuts, M. F. (2005). A discrete-time model for common lifetime inventory systems. Mathematics of Operations Research, 30(3), 718-732. doi: 10.1287/moor.1040.0133

Lian, Z., Liu, X., \& Zhao, N. (2009). A perishable inventory model with Markovian renewal demands. International Journal of Production Economics, 121(1), 176-182. doi: 10.1016/j.ijpe.2009.04.026

Liu, L. (1990). (s, S) continuous review models for inventory with random lifetimes. Operations Research Letters, 9(3), 161-167. doi: 10.1016/0167-6377(90)90014-v

Liu, L., \& Lian, Z. (1999). (s, S) continuous review models for products with fixed lifetimes. Operations Research, 47(1), 150-158. doi: 10.1287/opre.47.1.150

Liu, L., \& Yang, T. (1999). An (s, S) random lifetime inventory model with a positive lead time. European Journal of Operational Research, 113(1), 52-63. doi: 10.1016/s0377-2217(97)00426-8

Molana, S. M. H., Davoudpour, H., \& Minner, S. (2012). An (r, nQ) inventory model for packaged deteriorating products with compound Poisson demand. Journal of the Operational Research Society, 63(11), 1499-1507. doi: $10.1057 /$ jors.2011.154

Nahmias, S. (Ed.). (2011). Perishable inventory systems (Vol. 160). New York: Springer. 
This is a copy of the 'post-print' (i.e., final authors' copy, after referee comments have been addressed):

Duong, L.N.K., Wood, L.C., and Wang, W.Y.C. (in press). A review and reflection on inventory management of perishable products in a

single-echelon model, International Journal of Operational Research.

Nepal, B., Murat, A., \& Chinnam, R. B. (2012). The bullwhip effect in capacitated supply chains with consideration for product life-cycle aspects. International Journal of Production Economics, 136(2), 318-331. doi: 10.1016/j.ijpe.2011.12.018

Olsson, F., \& Tydesjö, P. (2010). Inventory problems with perishable items: Fixed lifetimes and backlogging. European Journal of Operational Research, 202(1), 131-137. doi: 10.1016/j.ejor.2009.05.010

Ozer, O., \& Xiong, H. (2008). Stock positioning and performance estimation for distribution systems with service constraints. IIE Transactions, 40(12), 1141-1157. doi: 10.1080/07408170802322960

Pahl, J., \& Voß, S. (2014). Integrating deterioration and lifetime constraints in production and supply chain planning: A survey. European Journal of Operational Research, 238(3), 654-674. doi: 10.1016/j.ejor.2014.01.060

Parlar, M., Perry, D., \& Stadje, W. (2011). FIFO versus LIFO issuing policies for stochastic perishable inventory systems. Methodology and Computing in Applied Probability, 13(2), 405-417. doi: 10.1007/s11009-009-9162$\underline{2}$

Ramanathan, U., \& Ramanathan, R. (Eds.). (2014). Supply chain strategies, issues and models. London: Springer.

Ravichandran, N. (1995). Stochastic analysis of a continuous review perishable inventory system with positive lead time and Poisson demand. European Journal of Operational Research, 84(2), 444-457. doi: 10.1016/0377-2217(93)E0254-u

Ross, S. M. (2006). Introduction to probability models (10 ed.). New York: Elsevier.

Sazvar, Z., Baboli, A., \& Akbari Jokar, M. (2013). A replenishment policy for perishable products with non-linear holding cost under stochastic supply lead time. International Journal of Advanced Manufacturing Technology, 64(5-8), 1087-1098. doi: 10.1007/s00170-012-4042-2

Schmidt, C. P., \& Nahmias, S. (1985). (S - 1,S) policies for perishable inventory. Management Science, 31(6), 719-728. doi: 10.1287/mnsc.31.6.719

Towill, D. R., Zhou, L., \& Disney, S. M. (2007). Reducing the bullwhip effect: Looking through the appropriate lens. International Journal of Production Economics, 108(1), 444-453. doi: 10.1016/j.ijpe.2006.12.024

van Donselaar, K. H., \& Broekmeulen, R. A. C. M. (2014). Stochastic inventory models for a single item at a single location. (BETA publicatie : working papers ; 447). Retrieved June 26, 2014 http://cms.ieis.tue.nl/Beta/Files/WorkingPapers/wp_447.pdf

Weiss, H. J. (1980). Optimal ordering policies for continuous review perishable inventory models. Operations Research, 28(2), 365-374. doi: 10.2307/170452 